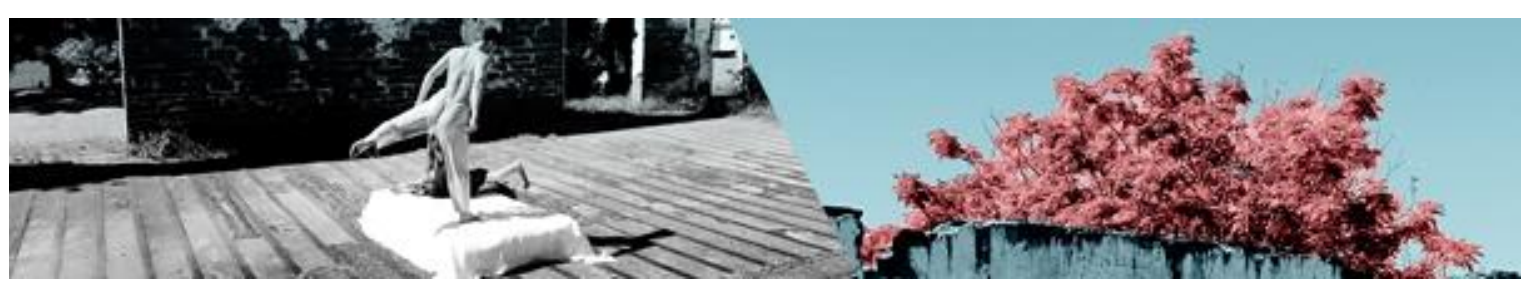

\title{
A DANÇA NA EDUCAÇÃO BÁSICA DA REDE PÚBLICA MUNICIPAL DE ENSINO DE TERESINA/PIAUÍ- UMA REALIDADE EM CRESCIMENTO
}

Resumo: Esse texto propõe reflexões acerca do processo de implantação da Dança enquanto disciplina integrante do currículo da educação básica, tendo como alicerce a concreta realização desse processo nas Escolas de Tempo Integral (ETIs) da Rede Pública Municipal de Teresina/Piauí, no ano de 2018. Partindo de alguns pensamentos provocados por diferentes autores e de documentos que norteiam os currículos e a historia da educação brasileira, passamos de um plano de ideias para um plano de ações concretas, no qual, pode-se perceber o potencial valor do hibridismo possível entre as áreas da Dança e da Educação, permeado por empecilhos que dificultam, mas não impedem aquela implantação.

Palavras-chave: Dança; Ensino Fundamental; Currículo.

\section{DANCE IN THE BASIC EDUCATION OF THE MUNICIPAL PUBLIC NETWORK OF TERESINA/PIAUÍ EDUCATION - A GROWING REALITY}

\begin{abstract}
This text proposes reflections about the implementation process of Dance as a discipline that is part of the curriculum of basic education, based on concrete realization of this process in the Schools of Integral Time (ETIs) of the Municipal Public Network of Teresina - Piauí, in the year of 2018. Starting from some thoughts provoked by different authors and documents that guide the curricula and the history of Brazilian education, we move from a plan of ideas to a plan of concrete actions, in which one can realise the potential value of a possible hybridism between the areas of Dance and Education, permeated by obstacles that hinder but not impede that implantation.

Keywords: Dance; Elementary School; Curriculum.
\end{abstract}

O corpo é o ponto zero do mundo, lá onde os caminhos e os espaços se cruzam.

Michel Foucault

\footnotetext{
${ }^{1}$ Mestre em Artes Cênicas (UnB/2017). Especialista em Metodologia de Ensino Fundamental, Médio e Superior (FAESPI/2003). Graduado em Licenciatura Plena em Educação Física (UFPI/1997). É professor da Rede Pública Municipal de Ensino de Teresina (SEMEC) e da Universidade Paulista (UNIP); integrante do Observatório das Juventudes, violências e Cultura de Paz nas Escolas (OBJUVE/CCE-UFPI). Autor dos livros: "Arte, Educação e Inclusão - 10 anos de Cordão Grupo de Dança" (2018) e "OUSADIA - vinte anos de História do Balé da Cidade de Teresina" (2014), dentre outras publicações.
}

FREITAS, Roberto. A Dança na Educação Básica da rede pública municipal de ensino de Teresina/Piauí- uma realidade em crescimento. Revista da FUNDARTE, Montenegro, p.298-315, ano 19, no 37, Janeiro/Março.

Disponível em: http://.seer.fundarte.rs.gov.br/index.php/RevistadaFundarte/index> 30 de março de 2019. 


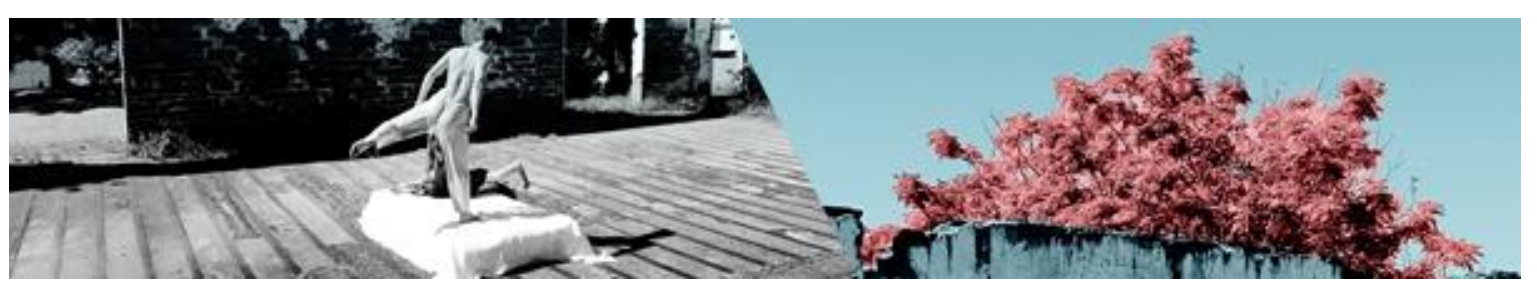

O ensino de dança na educação básica do município de Teresina - Piauí, há muitos anos, vem criando trajetórias que fortalecem o pensamento desta arte como um potencial meio educativo, seja no âmbito do desenvolvimento corporal e artístico, seja como estratégia em processos de ensino e de aprendizagem a serviço de conteúdos de outras disciplinas, ou mesmo com outras finalidades; tal como funcionam alguns projetos de cunho social voltados para o ensino da dança nas escolas.

Considerando aqui o termo "corpo" como se referindo à própria pessoa (LE BRETON, 2013), colocar um corpo para estudar seus próprios movimentos, para dançar, é interferir diretamente no modo como este corpo se relaciona com o meio que o rodeia, é, portanto, interferir em sua formação, sua própria vida. Colocar um corpo para dançar é oportunizar um maior conhecimento de si e, consequentemente, de suas relações com o mundo.

Uma criança, um jovem ou mesmo um adulto que estuda/vivencia a dança, para além de uma sensibilidade temporo espacial ${ }^{2}$ mais desenvolvida, relativo a conceitos ligados à ideia de consciência corporal, aprende também a melhor se reconhecer enquanto corpo (humano) e a se relacionar com outros corpos (humanos e não humanos; ou seja, não somente com as outras pessoas como também com todo tipo de corpo) que compõe o meio a seu redor. Tanto esse reconhecimento como essas relações tornam-se acontecimentos de extrema importância quando se pensa a formação integral de uma pessoa, em seu desenvolvimento pleno enquanto cidadã, aqui utilizando o pensamento contido no artigo 205 da Constituição Federal (BRASIL, 2013). Porém, o que se pode perceber ao longo da história da educação, e aqui se considera principalmente as quatro últimas décadas, é uma continuidade de processos que, em sua grande maioria, privilegiam o desenvolvimento do domínio cognitivo como que separado e/ou de valor superior ao desenvolvimento corporal (dualismo cartesiano).

Felizmente, a resistência de muitos estudiosos tem assegurado um mínimo de debate que, com a homologação, em 2017, da Base Nacional Comum Curricular -

\footnotetext{
${ }^{2}$ A utilização da marca tipográfica (til), nas conexões de alguns binômios desse texto, representa a possibilidade de caminhos rizomáticos, caminhos múltiplos, sinuosos e não lineares, para pensar aquelas conexões. Para mais informações ver Freitas (2017, p. 18).
}

FREITAS, Roberto. A Dança na Educação Básica da rede pública municipal de ensino de Teresina/Piauí- uma realidade em crescimento. Revista da FUNDARTE, Montenegro, p.298-315, ano 19, no 37, Janeiro/Março.

Disponível em: http://.seer.fundarte.rs.gov.br/index.php/RevistadaFundarte/index> 30 de março de 2019. 


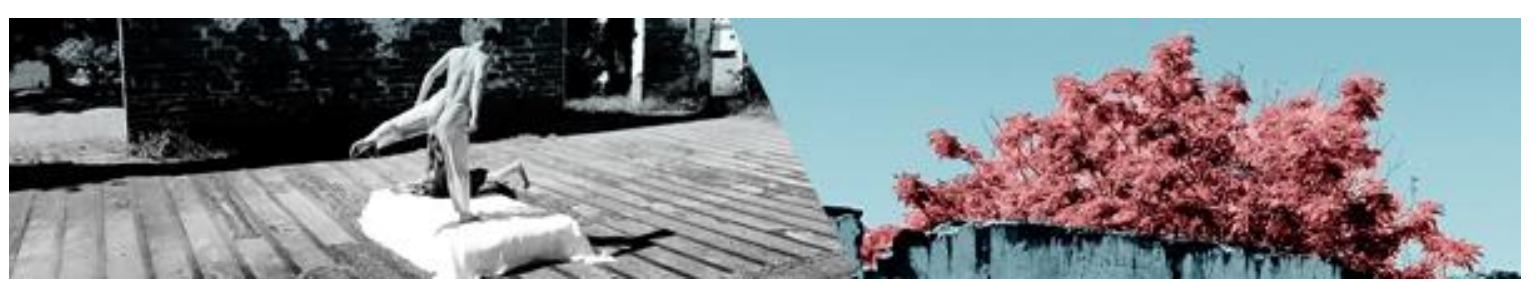

BNCC (BRASIL, 2018) - documento oficial destinado a nortear os currículos educacionais em todo o Brasil - parece ter crescido o entendimento de que 0 desenvolvimento do corpo de uma pessoa, não só tem diversos e diferentes domínios, como todos eles estão relacionados entre si, atravessando-se de modo que, mesmo não intencionalmente, potencializam-se uns aos outros. Desta forma, atinge-se o objetivo educativo que busca o pleno desenvolvimento de uma pessoa, citado na Constituição Federal do Brasil, mais conhecido sob o termo de Educação Integral.

Este texto propõe reflexões acerca do processo de implantação da Dança enquanto disciplina integrante do currículo da educação básica, tendo como base a concreta realização desse processo nas Escolas de Tempo Integral (ETIs) da Rede Pública Municipal de Teresina/Piauí, no ano de 2018.

\section{UMA BREVE DANÇA COM DOCUMENTOS E PENSAMENTOS EM EDUCAÇÃO}

Teresina, capital do Piauí, é uma cidade que produz muita arte em diversas linguagens e seus hibridismos. Inúmeros artistas tiveram a semente de suas carreiras plantada no chão da escola formal, onde, por meio de atividades ou projetos curriculares ou extracurriculares, germinaram seu broto e/ou se desenvolveram a partir daquele ambiente. Tal acontecimento constitui um caminho para possíveis interações entre arte e educação. Porém, relativo à instrução de dança nas escolas de ensino formal, em muitos casos, ocorrem equívocos que, mesmo para alguns gestores e/ou arte-educadores, que não vivenciam a dança de forma cotidiana ou profissional, podem passar despercebidos, muitas vezes pela própria falta de conhecimento.

Um exemplo dos equívocos cometidos é a forma de tratar a dança na escola: somente como atividade de entretenimento, na busca de elaborar trabalhos coreográficos para apresentação em alguma data festiva, enfatizando apenas o seu caráter espetacular. Ao contrário desse modo de agir, ao se pensar a dança como um caminho possível de educação- ou mesmo de experimentação da vida- na escola, para muito além de se educar ou disciplinar um corpo, facilmente se pode descobrir a força transformadora que pode ter a utilização desta arte enquanto meio facilitador de processos de formação: processos de ensino/aprendizagem que visem

FREITAS, Roberto. A Dança na Educação Básica da rede pública municipal de ensino de Teresina/Piauí- uma realidade em crescimento. Revista da FUNDARTE, Montenegro, p.298-315, ano 19, no 37, Janeiro/Março.

Disponível em: http://.seer.fundarte.rs.gov.br/index.php/RevistadaFundarte/index> 30 de março de 2019. 


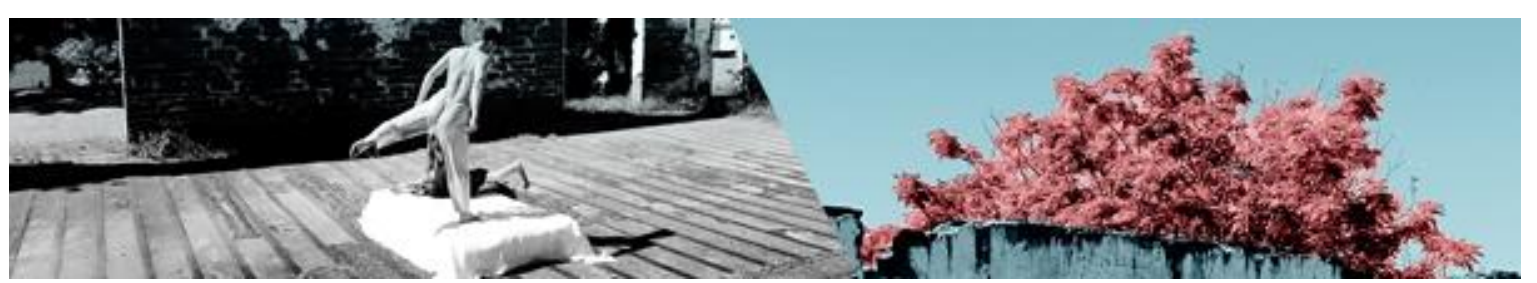

a educação integral, o pleno desenvolvimento da pessoa em todos os seus domínios, do corporal ao sócio emocional.

Ao refletir sobre o ensino de dança nas escolas de educação básica, já na presente década, Isabel Marques propõe questões que se comunicam com teorias críticas, pós-modernas e multiculturalistas. Dentre outras, a autora questiona:

- Como trazer a dança para a escola básica sem que se torne uma disciplina a mais no currículo, esmagada pelos horários, pela falta de infraestrutura, pelo despreparo dos professores, pela falta de motivação dos alunos? [...]

- Como valorizar o conhecimento autorreflexivo, inscrito no corpo, parcial, aberto, em nossas práticas de dança na escola? (MARQUES, 2011, p. 22-23).

As reflexões de Marques, para além de seus questionamentos, que por si só já constituem um relevante leque de pensamentos, nos levam a perceber intenções, contidas em uma dança educação possível, intenções que se comunicam diretamente com objetivos propostos pelos documentos oficiais que regem a educação brasileira, desde a Constituição Federal (já citada), passando pelos Parâmetros Curriculares Nacionais (PCNs), e chegando à BNCC, dentre outros. Nesse sentido, Márcia Strazzacappa e Carla Morandi ressaltam informações contidas nos PCNs-Arte/1998 quando colocam que "a escola está encarregada não de reproduzir, mas de instrumentalizar e de construir conhecimento em dança e por meio da dança com seus alunos" (STRAZZACAPPA; MORANDI, 2012, p. 72-73), enfatizando ainda possibilidades de diálogos com os próprios conteúdos específicos da dança, o que, aqui relacionando com a BNCC, pode promover um desenvolvimento crítico de estudantes e sua apropriação de atitudes e habilidades que permeiam a atuação de cidadãos conscientes de seu papel em sociedade; em outras palavras, as relações entre seu corpo e o mundo que o rodeia.

Outra preocupação que é comum, tanto a estudiosos da área da dança quanto a documentos oficiais que regulamentam a educação brasileira, é a necessidade das práticas educativas levarem em conta a bagagem cultural do próprio estudante, o que Kenneth Zeichner chamaria de "Background etnocultural" (1993), ou seja, é importante pensar as experiências para educação de um corpo,

FREITAS, Roberto. A Dança na Educação Básica da rede pública municipal de ensino de Teresina/Piauí- uma realidade em crescimento. Revista da FUNDARTE, Montenegro, p.298-315, ano 19, no 37, Janeiro/Março.

Disponível em: http://.seer.fundarte.rs.gov.br/index.php/RevistadaFundarte/index> 30 de março de 2019. 


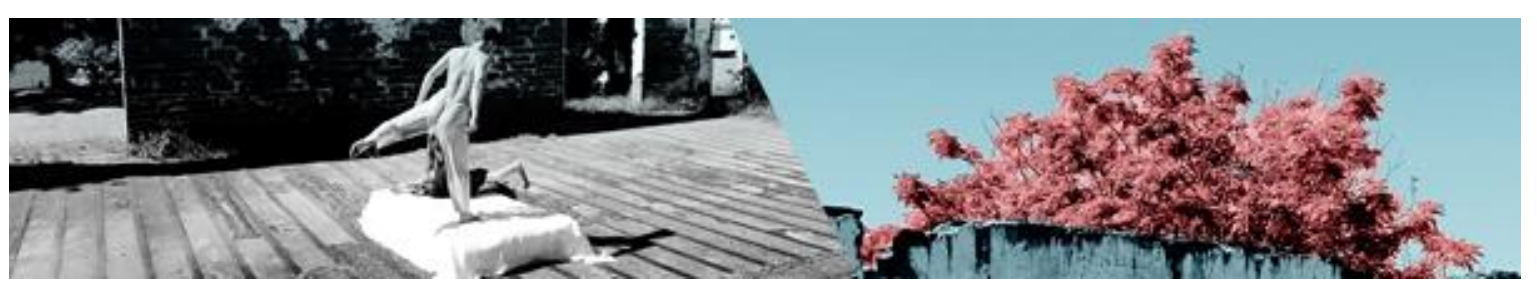

uma pessoa, considerando que esse corpo já traz consigo não só certa quantidade de informações, mas também de desejos, e que, dependendo das informações e desejos contidos nesse corpo, determinada estratégia de ensino pode não atingi-lo, não lhe causando uma experiência significativa. E mais, em se tratando de jovens estudantes que vivem a contemporaneidade, é perceptível que cada vez mais cresce o desinteresse por informações que não se comunicam com seus desejos pessoais, situação que provoca, nesses jovens, desinteresse pela própria educação, o que pode ocasionar evasão escolar ou, no mínimo, atitudes de rejeição a determinadas práticas educativas propostas pelos professores ou mesmo pela escola.

Ao ponderar sobre as relações possíveis entre as ideias até aqui colocadas, sou remetido ao pensamento sobre o "saber de experiência", de Jorge Larrosa Bondía (2002). Acredito que a experiência, a vivência prática de um corpo, a experimentação in loco das situações da vida, impõem-se como fundamental para a formação de qualquer corpo. Penso que, em qualquer que seja a área de estudo, caso uma aula seja considerada "chata" (posicionamento de alguns estudantes), sem atrativos, mesmo o professor sendo um exímio conhecedor do conteúdo, tal aula terá um grande empecilho para atingir seu objetivo maior: a aprendizagem dos estudantes. Assim, ao ser considerada "chata", a aula irá ao encontro do próprio interesse do estudante em aprender. Por outro lado, caso a aula seja proposta por meio de algum processo criativo que provoque o estudante a ter atitude e a posicionar-se diante daquela situação, ou seja, experimentar aquela vivência de forma mais coesa (de corpo inteiro), aquela situação acabará por se tornar mais significativa para aquele corpo, o que aumentará as chances de aprendizagem ou, no mínimo, de despertar o interesse dos estudantes para as questões colocadas.

Pensar em processos educativos tratando os corpos como depósitos de informações seria não considerar esses corpos como vivos, não entendendo que estão em pleno processo formação, de desenvolvimento dinâmico; seria atuar por meio do que Paulo Freire denominou, em sua "Pedagogia do Oprimido", de "educação bancária" (1987), o que acabaria por se tornar um instrumento de opressão e, desta forma, atuaria na contramão de uma educação para o entendimento crítico da realidade. Como não considerar as informações que os

FREITAS, Roberto. A Dança na Educação Básica da rede pública municipal de ensino de Teresina/Piauí- uma realidade em crescimento. Revista da FUNDARTE, Montenegro, p.298-315, ano 19, no 37, Janeiro/Março.

Disponível em: http://.seer.fundarte.rs.gov.br/index.php/RevistadaFundarte/index> 30 de março de 2019. 


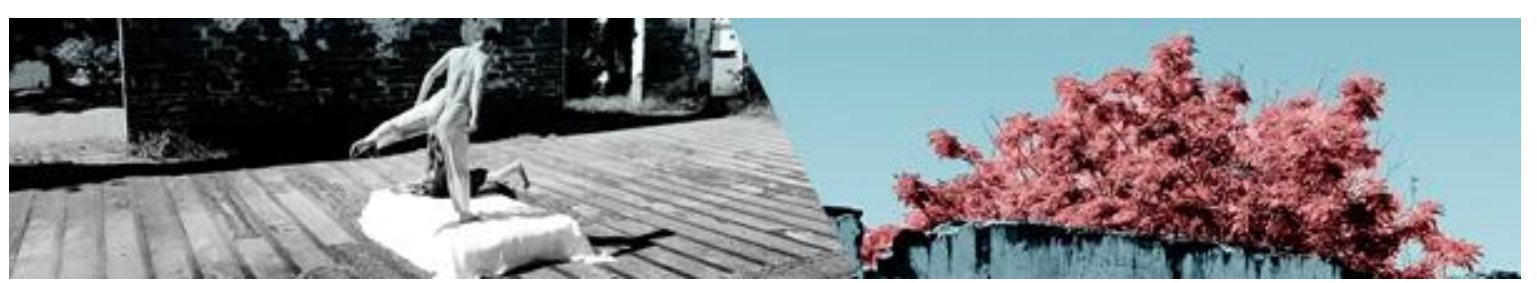

estudantes já trazem consigo, em seus corpos? Como não considerar suas verdades, suas experiências, as realidades vividas por esses corpos?

Em oposição a qualquer ideia de opressão, a BNCC pauta um ensino que opere pelo desenvolvimento de competências e, em consonância com pensamentos de educação em direitos humanos, pensa o processo educativo como transformador da sociedade, no intuito de torná-la mais humana. Com esse recorte:

Na BNCC, competência é definida como a mobilização de conhecimentos (conceitos e procedimentos), habilidades (práticas, cognitivas e socioemocionais), atitudes e valores para resolver demandas complexas da vida cotidiana, do pleno exercício da cidadania e do mundo do trabalho. (BRASIL, 2017, p. 8).

A partir de competências que podem levar um corpo a melhor se relacionar com o mundo, a BNCC reafirma a ideia de uma educação integral, destacando inclusive o rompimento com ideias reducionistas, como, por exemplo, priorizar a dimensão cognitiva. Esse pensamento, de não reduzir a educação a processos que privilegiam o desenvolvimento cognitivo, reforça a ideia de que a educação deve "assumir uma visão plural, singular e integral da criança, do adolescente, do jovem e do adulto" (Ibid., p. 14), provocando e assumindo as possibilidades de novas formas de existir, respeitando assim a diversidade, as diferenças em geral.

Não só na dança como em outras áreas, tal como na Sociopoética ${ }^{3}$, considera-se todo o corpo como fonte de informação. O corpo produz e abriga os conhecimentos componentes daquele citado backgroud; um corpo que cria e é criado por vários atravessamentos, por conexões que se ligam e tecem uma rede de movimentos/pensamentos e, por este caminho, provocam fazeres - o "fazer-dizer do corpo" (SETENTA, 2008); um corpo que se movimenta em todas as áreas, da artística à educativa, por meio de processos que vão do domínio corporal ao cognitivo, e que, por meio de um pensamento de inclusão da própria vida, pode vir a conseguir a real formação integral de um corpo: o corpo cidadão.

\footnotetext{
${ }^{3}$ Metodologia de pesquisa que opera, dentre seus princípios básicos, com a ideia de que o corpo (humano) todo é fonte de produção e acolhimento de informações; nas palavras de Shara Jane Adad, relativo a pesquisas em educação: "um novo corpo-pesquisador que, mestiço, não separa o sujeito do objeto, como na pesquisa tradicional" (2014, p. 50).

FREITAS, Roberto. A Dança na Educação Básica da rede pública municipal de ensino de Teresina/Piauí- uma realidade em crescimento. Revista da FUNDARTE, Montenegro, p.298-315, ano 19, no 37, Janeiro/Março.

Disponível em: http://.seer.fundarte.rs.gov.br/index.php/RevistadaFundarte/index> 30 de março de 2019.
} 


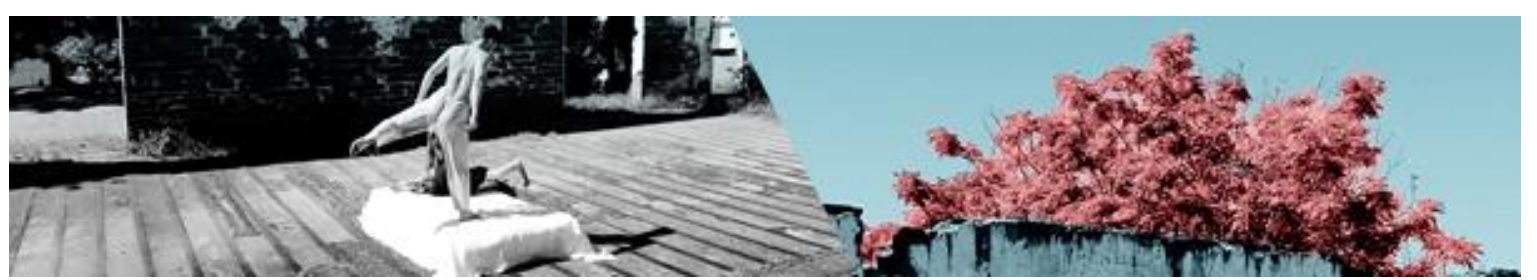

\section{DAS TEORIAS ÀS AÇÕES}

A história da implantação, no Brasil, de escolas que trabalhem em regime de Tempo Integral, é recheada de atravessamentos (pensamentos, discussões, análises e outros) que dialogam com inúmeros conceitos em educação, dentre os quais destaco a "educação integral", já citada nesse texto, por se tratar de um pensamento que diretamente se comunica com a ideia de dança educação. Para Juliana Santos, a ideia de Educação Integral:

[...]firma-se em 1932, quando do marco histórico do Manifesto dos Pioneiros da Educação Nova. Anísio Teixeira, na década de 50, idealizou as Escolas Parque na Bahia e na década de 80, Darcy Ribeiro, implementou os Centros Integrados de Educação Pública (CIEPs) no Rio de Janeiro, ambos vislumbravam um Brasil educado e democrático. (SANTOS, 2013, p. 2).

Permeando aquela história, um ideal de escola que promova a real educação integral dos estudantes vem sendo refletido e debatido. No entanto, como também comenta Santos, a maioria das iniciativas acaba por estancar em um dos principais problemas brasileiros, que é a falta de continuidade nas políticas públicas, ficando o desenvolvimento da potencialidade de alguma iniciativa a cargo da vontade pessoal de um determinado gestor, e não de uma política de estado, como deveria ser.

$\mathrm{Na}$ Rede Pública Municipal de Ensino de Teresina, após um período de estudos, planejamentos, diálogos e algumas experimentações apoiadas pela visão educativa de Kleber Montezuma, então Secretário Municipal de Educação, o início do ano letivo de 2018, foi marcado pela instituição do Tempo Integral em 10 Escolas da rede que, atualmente, conta com 309 unidades de ensino (dentre as Escolas de Educação Infantil e de Ensino Fundamental - incluídas aqui as ETIs), ressaltando, ainda, que em 2019 serão em número de 16.

Tomando por base as informações contidas em documentos, como a Lei de Diretrizes e Bases da Educação Nacional (1996) e o Plano Nacional de Educação (2001), dentre outros, e também levando em consideração alguns currículos já implantados em escolas de outros estados, que funcionavam em tempo integral, a equipe de trabalho da Secretaria Municipal de Educação - SEMEC/Teresina, que foi designada para efetivar aquela implantação, para além das informações obtidas

FREITAS, Roberto. A Dança na Educação Básica da rede pública municipal de ensino de Teresina/Piauí- uma realidade em crescimento. Revista da FUNDARTE, Montenegro, p.298-315, ano 19, no 37, Janeiro/Março.

Disponível em: http://.seer.fundarte.rs.gov.br/index.php/RevistadaFundarte/index> 30 de março de 2019. 


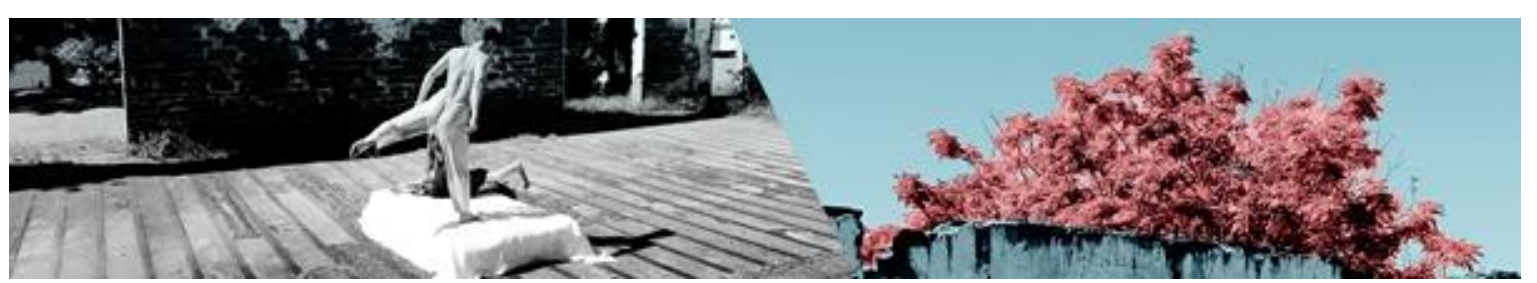

naqueles documentos, refletiu sobre uma questão que, naquele momento, sem ser de seu conhecimento, já estava inclusa na nova BNCC: a importância da utilização de diferentes linguagens para uma leitura de mundo, quesito básico numa educação que se pretenda integral.

Naquele sentido, e principalmente pensando na formação de crianças e jovens, nas fases do desenvolvimento humano onde ocorrem com maior liberdade momentos de abertura para uma leitura de mundo, não tenho como não citar as palavras de Paulo Freire em seu "a importância do ato de ler [...]" quando coloca que:

Os "textos", as "palavras", as "letras" daquele contexto se encarnavam no canto dos pássaros - o do sanhaçu, o do olha-pro-caminho-quem-vem, o do bem-te-vi, o do sabiá; na dança das copas das árvores sopradas por fortes ventanias que anunciavam tempestades, trovões, relâmpagos; as águas da chuva brincando de geografia: inventando lagos, ilhas, rios, riachos. (1989, p. $9-10$ - grifos do autor).

A dança produzida pelo movimento dos corpos do mundo - ideias que brotam a partir das palavras de Freire e suas consequentes leituras, interpretações individuais das pessoas - também inspirou, simbolicamente, a equipe liderada por Maria Eliane dos Santos Araújo, a focar na utilização de diferentes linguagens como aposta para suprir as demandas de experiências (estudos/vivências em diferentes matérias) a serem ofertadas nas ETls, no intuito de complementar o tempo de permanência dos estudantes na escola. Foi então criado o que seria chamado de "núcleo diversificado" (ARAÚJO, 2019), composto pelas seguintes áreas de conhecimento (disciplinas): Dança, Desenho, Iniciação Musical, Projeto de Vida e Protagonismo Juvenil, Teatro e Xadrez.

A ideia de diversificar as formas de como os estudantes interagem com 0 mundo, de como experimentam suas relações com os outros corpos existentes, suas leituras e interpretações, veio também para suprir a notória necessidade de desenvolvimento do que a BNCC chama de Competências Socioemocionais, e que, a nosso ver, bem como nas palavras de Eliane Araújo (2019), alia os domínios inerentes a uma educação integral, que também podemos denominar desenvolvimento humano, do corporal ao cognitivo, dentre outros.

FREITAS, Roberto. A Dança na Educação Básica da rede pública municipal de ensino de Teresina/Piauí- uma realidade em crescimento. Revista da FUNDARTE, Montenegro, p.298-315, ano 19, no 37, Janeiro/Março.

Disponível em: http://.seer.fundarte.rs.gov.br/index.php/RevistadaFundarte/index> 30 de março de 2019. 


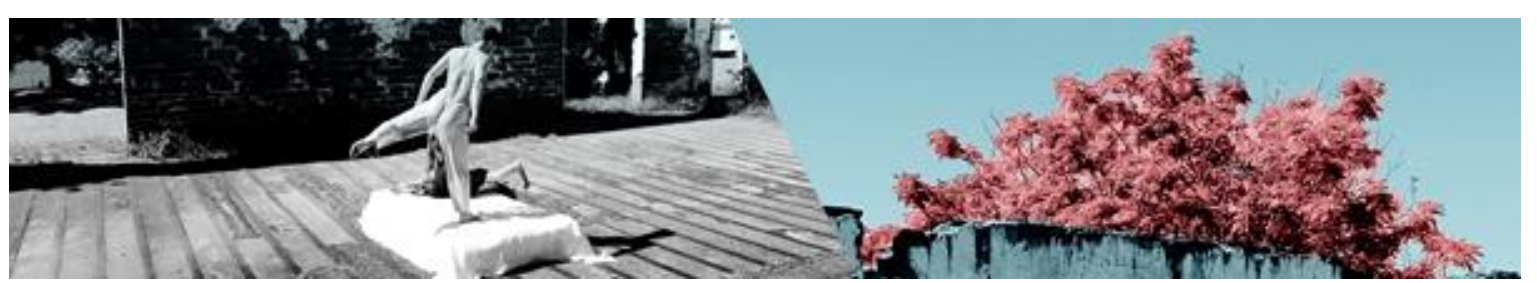

As outras matérias, que não chamarei de disciplinas devido ao fato deste termo estar carregado de ideias colonizadoras, compõem um núcleo que é comum, obrigatório, como os estudos em história e geografia, por exemplo. Ambos os núcleos, comum e diversificado, são pensados como componentes de uma mesma conexão que, embora não praticada por todos os educadores da rede ${ }^{4}$, foi pensada com o intuito de se desenvolver por meio do atravessamento de todos os domínios do desenvolvimento humano, sem o privilégio de esta ou aquela área ser considerada como prioritária em determinado domínio (como o pensamento de que a matemática é puro raciocínio lógico - domínio cognitivo - ou a dança só desenvolveria o domínio físico-motor). Tais pensamentos, que ainda vejo e ouço atualmente, em ambientes de diversas escolas, provocam-me a pensar, dentre outras questões: Matemática não pode ser arte? A dança não desenvolve o domínio cognitivo? Em atividades de raciocínio lógico não se pode trabalhar questões socioemocionais?

No início do ano de 2018, cinco professores concursados e integrantes da Rede Pública Municipal de Ensino de Teresina, junto a um artista local, que por meio de parceria/convênio firmado com a SEMEC/Teresina gerenciava um projeto na área de Teatro, foram convidados para uma reunião da qual saíram com a desinência de "professores referência" (ARAÚJO, 2019), termo utilizado para designar as pessoas que realizariam a coordenação das equipes que iriam compor o grupo de professores de cada área do núcleo diversificado. Caminhos propostos, desafios aceitos, passamos então do plano das teorias para o plano das ações.

\section{FLUXOS E CORTES EM UMA POSSÍVEL DANÇA EDUCAÇÃO}

As conexões entre o ensino de Dança e a educação praticada na Rede Pública Municipal de Ensino de Teresina, há tempos vêm criando laços, rizomatizando trajetórias legítimas que aqui, devido ao formato do texto, farei apenas um pequeno recorte dessa realidade em crescimento.

\footnotetext{
${ }^{4}$ Aqui lembrando que currículos são propostas e que, muitas vezes, podem ser mal interpretadas ou, ainda, não aplicadas, dependendo não só da vontade individual de um professor, como também dos gestores da escola em questão.

FREITAS, Roberto. A Dança na Educação Básica da rede pública municipal de ensino de Teresina/Piauí- uma realidade em crescimento. Revista da FUNDARTE, Montenegro, p.298-315, ano 19, no 37, Janeiro/Março.

Disponível em: http://.seer.fundarte.rs.gov.br/index.php/RevistadaFundarte/index> 30 de março de 2019.
} 


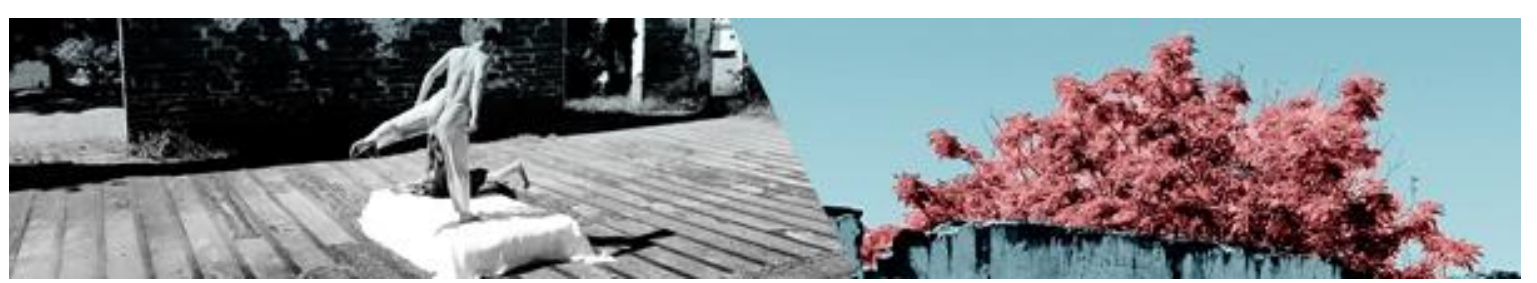

Além de outras iniciativas, nos anos de 2006 e 2008, foi realizado o Projeto "Educação se faz com Arte", que levou apresentações, oficinas (40 h/a) e mostra de dança para 25 escolas municipais, em cada ano. Esse projeto se deu mediante um convênio firmado entre a SEMEC/Teresina e a Associação dos Amigos do Balé da Cidade. Em 2005, na Escola Municipal Porfírio Cordão, foi criado o Cordão Grupo de Dança, que dentro de seus 14 anos de existência (Fev/2005 a Fev/2019) firmou um trabalho artístico, educativo e de inclusão, que tem sua validade já registrada em pesquisa/dissertação de mestrado, bem como em livro publicado (FREITAS; BREBIS, 2018). Essas atividades concretas, dentre outras realizadas, também serviram de inspiração para pensar o processo de implantação da Dança enquanto componente curricular da educação básica.

Em fevereiro de 2018, logo no início do processo surgiu uma problemática que já vem sendo identificada há muitos anos em nosso país: a falta de pessoal qualificado para assumir determinadas funções. Em 2014, o artigo "O Swing do Ensino de Dança no Brasil: um balanço de quase duas décadas", de Márcia Strazzacappa, já refletia sobre o fato de que, se as leis que vinham sendo propostas pelos documentos oficiais que regem a educação brasileira fossem realmente aplicadas, não haveria pessoal suficiente para suprir toda a demanda. Tal problema constituiu o primeiro corte no fluxo da implantação da dança enquanto área de estudo a compor o currículo das ETIs em Teresina. Porém, como em um rizoma (DELEUZE; GUATTARI, 2014), um corte acontece em um ponto, um broto nasce em outro.

Sem intenção direta, mas fomentando o mercado de trabalho para profissionais de dança, devido às necessidades apresentadas, a SEMEC/Teresina expandiu a oportunidade de estágios para além dos cursos de graduação em nível superior (tentativa já experimentada naquele momento). Com isso, também os estudantes da Escola Técnica Gomes Campos, que funciona com cursos em nível médio profissionalizante em Dança e Teatro, poderiam ser admitidos como estagiários. Após algumas incertezas de lotação de professores (graduados) e instrutores (nível médio) - aqui tratarei a todos como professores - passamos à implantação concreta: a ida para as salas de aula, que, juntamente com o processo de capacitação daqueles mesmos integrantes da equipe coordenados pelos

FREITAS, Roberto. A Dança na Educação Básica da rede pública municipal de ensino de Teresina/Piauí- uma realidade em crescimento. Revista da FUNDARTE, Montenegro, p.298-315, ano 19, no 37, Janeiro/Março.

Disponível em: http://.seer.fundarte.rs.gov.br/index.php/RevistadaFundarte/index> 30 de março de 2019. 


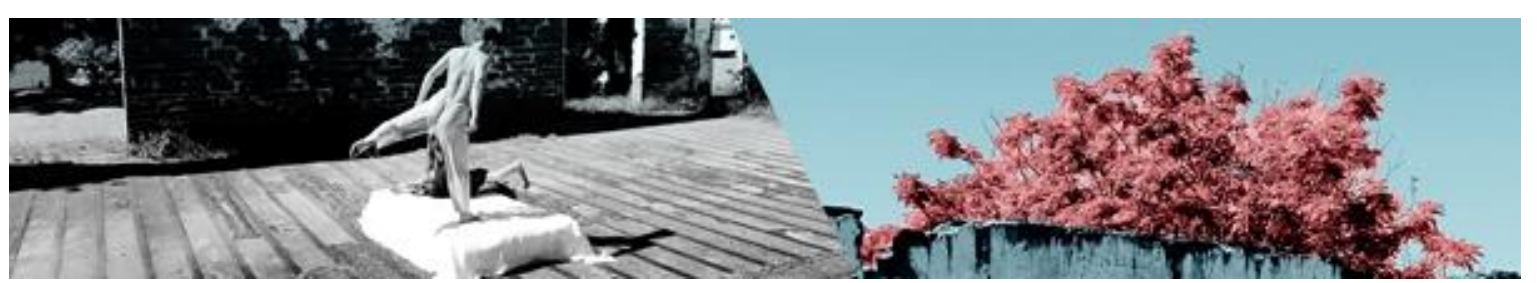

professores referência, transformou o ano de 2018 em um grande laboratório de pesquisas em educação e arte.

Iniciamos a capacitação de Dança com uma equipe composta por dez pessoas: quatro professores concursados, que são do quadro efetivo da rede, cinco estagiários - um deles já desenvolvia um trabalho permanente de dança em uma das ETls - e, ainda, um professor referência (coordenador). Nossa equipe, relativo à formação acadêmica, era composta por duas professoras e um professor graduados em Educação Física e um professor graduado em Artes (todos com pouca experiência com dança), e, ainda, o professor referência graduado em Educação Física, mestre em Artes Cênicas e artista profissional da dança havia 28 anos. Dentre as outras cinco pessoas, uma delas já tinha experiência como dançarina e professora de dança, uma era estudante de Educação Física e as outras três eram alunas do citado curso técnico. Todas eram estagiárias suprindo a necessidade que não conseguiu ser preenchida por estudantes de nível superior. Vale registrar que, em Teresina, dentre as áreas que compõem o núcleo diversificado do currículo das ETIs, somente a Iniciação Musical tem um correspondente curso em nível superior.

É perceptível que aquela decisão, relativa à lotação de professores e composição da equipe de trabalho, acabou por se constituir tanto em uma solução como em um novo problema. Os estudantes do curso técnico, talvez devido à falta de uma preparação pedagógica (não descartando aqui o interesse pessoal de cada um para a atividade docente), apresentaram muitas dificuldades, não no conteúdo da Dança em si, mas na lida com os estudantes, ou seja, no domínio de turma. Enquanto os professores graduados lidavam melhor com as questões pedagógicas, os estagiários destacavam-se no domínio do conteúdo de dança. Esse dois pontos constituem o principal motivo que gerou um fluxo de entradas e saídas de professores na equipe. Notou-se, com isso, um grande prejuízo, pois ao final do ano, dezesseis pessoas haviam passado pelo grupo, e, algumas, dentre as nove que chegaram ao final do processo, frequentaram a capacitação apenas uma ou duas vezes. Durante o ano houve ainda o afastamento de uma das ETIs, que decidiu seguir sozinha, separada da programação que nós estávamos compartilhando.

A capacitação foi pensada para continuamente tentar suprir as necessidades de formação dos professores quanto aos conteúdos de dança a serem abordados, a

FREITAS, Roberto. A Dança na Educação Básica da rede pública municipal de ensino de Teresina/Piauí- uma realidade em crescimento. Revista da FUNDARTE, Montenegro, p.298-315, ano 19, no 37, Janeiro/Março.

Disponível em: http://.seer.fundarte.rs.gov.br/index.php/RevistadaFundarte/index> 30 de março de 2019. 


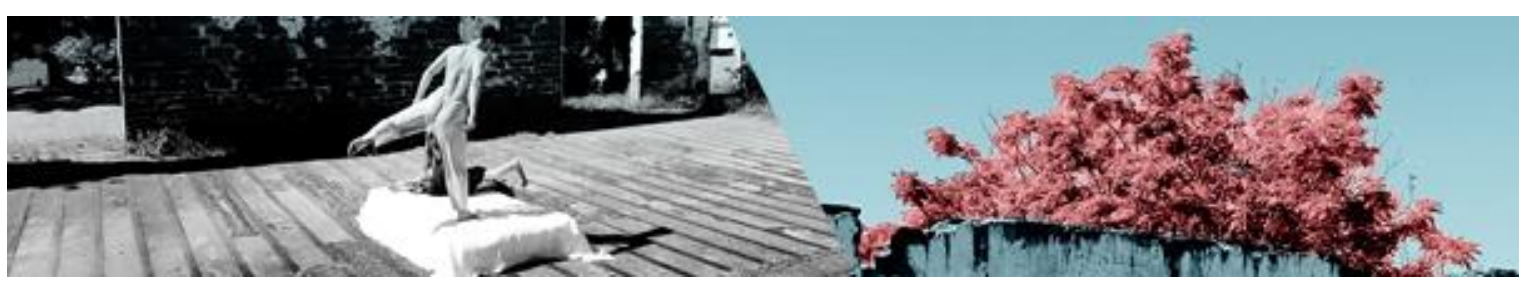

metodologia a ser utilizada e outras questões que surgissem. Essa formação inicialmente foi pensada para cinco encontros durante o ano, com quatro horas de duração cada. Ao refletir sobre a magnitude de tal empreendimento, a implantação da dança enquanto componente curricular das ETIs, Roberto Freitas (professor referência da equipe de Dança) propôs uma expansão nessa carga horária e, após aceitação da SEMEC/Teresina e dos professores da equipe, instituímos uma carga horária de 60 horas: 20 horas prioritariamente para estudos de teorias e elaboração dos Planos de Ensino em equipe (cinco encontros), 20 horas para experimentações de atividades práticas (cinco encontros) e mais 20 horas para estudos, planejamentos e outras produções individuais.

Ao avaliar aquele processo de capacitação, em uma dinâmica sem a identificação dos autores dos depoimentos, pôde-se perceber que, dentre os pontos positivos, estão a troca de experiências, os planejamentos acerca dos conteúdos a serem propostos na lida concreta das aulas e o cumprimento do cronograma proposto. Relativo aos pontos negativos, a equipe foi unânime em citar o tempo da capacitação como insuficiente, requisitando mais tempo para estudos/experimentações teórico-práticas, posicionamento que, a meu ver, concorda com a ideia de que a falta de (in)formação em dança é o principal corte no fluxo do interesse em ministrar aulas nessa área, realidade vivida inclusive pelos professores graduados em Educação Física. Quanto ao pedido de sugestões para melhoria do processo de capacitação, novamente aparece como principal fator a problemática do tempo versus "a valiosa contribuição das aulas práticas" (depoimento coletado em atividade avaliativa do processo de capacitação, realizado em 08 de junho de 2018).

É perceptível, entre os professores concursados no município de Teresina, a carência de formação para desenvolver a Dança enquanto componente curricular da educação básica. Essa realidade se apresenta de forma a mostrar que já se pode pensar em concurso público para professor de Dança, não só em Teresina, mas em todo o Brasil, já que em 2014 já existiam "44 graduações, segundo os dados do Instituto Nacional de Estudos e Pesquisas Educacionais (Inep)" (STRAZZACAPPA, 2014, p. 94). Contudo, em Teresina, mesmo sem uma licenciatura em Dança, existem inúmeros profissionais que, mesmo sendo graduados em outras áreas, facilmente poderiam comprovar sua experiência com dança, podendo, para efeito de

FREITAS, Roberto. A Dança na Educação Básica da rede pública municipal de ensino de Teresina/Piauí- uma realidade em crescimento. Revista da FUNDARTE, Montenegro, p.298-315, ano 19, no 37, Janeiro/Março.

Disponível em: http://.seer.fundarte.rs.gov.br/index.php/RevistadaFundarte/index> 30 de março de 2019. 


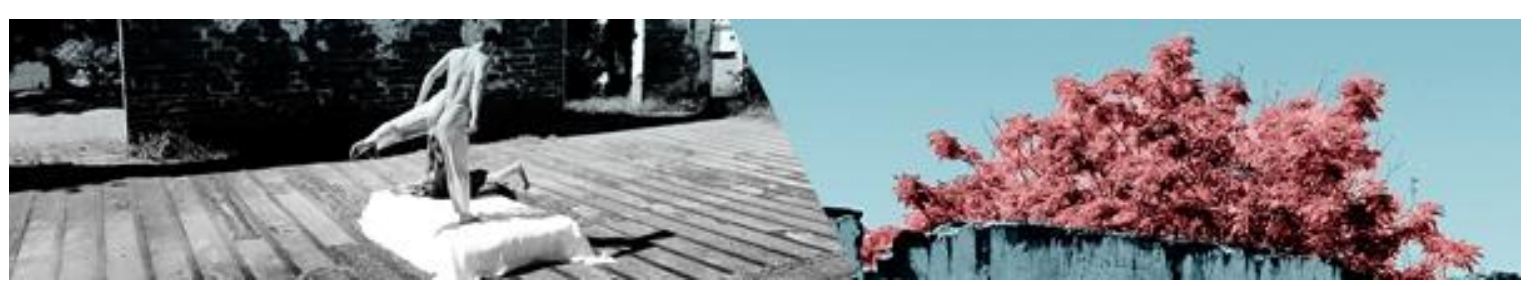

concurso, ser amparados pela Lei dos Artistas (Lei federal $n^{\circ}$ 6.533, de 24 de maio de 1978) e, assim, fomentar o crescimento desse mercado de trabalho para os profissionais dessa área de conhecimento - função do Estado.

\section{(IM)PLANTANDO DANÇA PARA COLHER CIDADÃOS}

Ao levar em consideração todas as informações já compartilhadas nesse texto, pode-se imaginar o tamanho do desafio que essa implantação assumiu. No entanto, novamente pensando sobre a ideia de um saber de experiência (BONDíA, 2002), para qualquer início de um novo caminho é preciso dar o primeiro passo, é preciso experimentar e compor esse saber. Os resultados já apresentados aqui, acerca da avaliação do processo de capacitação dos professores, já trouxeram pistas para se pensar como realmente aconteceu esse procedimento in loco, como foi plantar a Dança no chão das escolas municipais em Teresina, enquanto componente curricular.

Uma primeira decisão tomada, que corrobora com as questões já colocadas, foi de que não seria possível instituir as aulas em todos os anos de ensino e, consequentemente, haveria uma divisão. Os estudos em Dança, no ano de 2018, foram ministrados nos primeiros, segundos, terceiros, sextos e sétimos anos do ensino fundamental, o que, levando em conta as $10 \mathrm{ETI}$ de Teresina, somam um total de 63 turmas e, considerando uma média de 35 estudantes por turma, totaliza um número de 2.205 crianças e/ou adolescentes atendidos.

Relativo à satisfação dos estudantes, acredito ser possível sintetizar aquela experiência (de ter aulas de dança em uma instituição formal de ensino) em uma frase: "alunos de outras turmas quiseram fazer um abaixo-assinado para terem aula de dança" (depoimento da professora Juliana Maria de Andrade Soares durante os encontros da capacitação). Mediante os depoimentos da equipe, é perceptível que certa euforia tomou de conta das crianças e jovens quando perceberam que poderiam dançar em suas aulas, que poderiam ter aulas de dança na própria escola, dentro do horário de estudo. Mesmo depois de passado o momento inicial, ao se depararem com a ideia de que a Dança seria algo maior do que simplesmente reproduzir passos coreografados, códigos de alguma técnica de dança específica ou

FREITAS, Roberto. A Dança na Educação Básica da rede pública municipal de ensino de Teresina/Piauí- uma realidade em crescimento. Revista da FUNDARTE, Montenegro, p.298-315, ano 19, no 37, Janeiro/Março.

Disponível em: http://.seer.fundarte.rs.gov.br/index.php/RevistadaFundarte/index> 30 de março de 2019. 


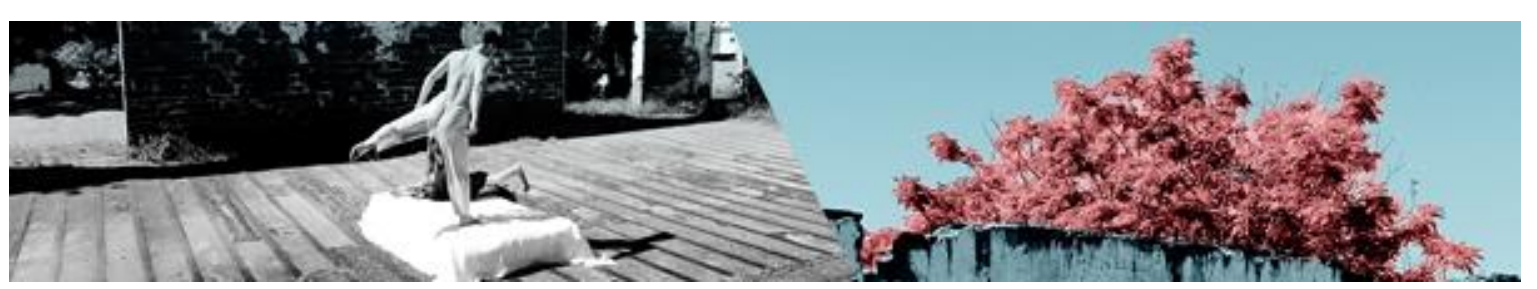

mesmo uma dança popular - como as coreografias que acompanham determinadas músicas de funk ou outro gênero musical - constatar no próprio corpo que a dança traz um maior conhecimento de si e das suas relações com o mundo causou, em muitos estudantes, uma transformação de comportamento e atitudes com relação à forma de lidar com os colegas de turma, e até consigo mesmo.

Como já mencionado, colocar um corpo para dançar é interferir em sua vida, na sua forma de ver e se relacionar com o mundo, na sua cultura, pois:

O processo de constituição do sujeito se dá num espaço de agência onde traços e referências dos dois ambientes (corpo e cultura) estão conectando pedaços, partes, fragmentos de inúmeras informações, um do outro, que vão organizando a fala do corpo, um corpo atravessado por experiências distintas de idas e vindas, expressando o pensamento crítico e reflexivo. (SETENTA, 2008, p. 61).

Colocar um corpo para dançar é dar oportunidade a este corpo de refletir e se (re)inventar, para além dos conceitos pré-estabelecidos pelas sociedades em que vivemos, que, ainda na contemporaneidade, em sua grande maioria, atua por meio de fazeres colonizadores, e a educação não fica de fora desse meio.

A partir dos depoimentos da equipe de professores de Dança é possível afirmar que os estudantes que participaram das aulas extrapolaram as expectativas, demonstrando, em palavras e atitudes, não terem problemas de aceitação desta arte como área de estudo. Pelo contrário, mais de $90 \%$ não só participaram como também demonstraram gostar e se divertir com as atividades propostas nas aulas, mesmo algumas delas sendo prioritariamente teóricas. Alguma resistência relatada não diz respeito à aplicação da dança enquanto aula em si, mas foi observado certo estranhamento ao início do trabalho de improvisação, no qual os estudantes deveriam assumir a posição de protagonistas de suas (cri)ações. $O$ fato de tal recusa acontecer apenas no início desse tipo de trabalho pode significar a falta de liberdade que, cotidianamente, muitos possuem: a possibilidade de se colocar criticamente, de poder falar abertamente sobre seus próprios pensamentos, desejos e posicionamentos críticos, refletindo e se expressando, como disse Setenta na citação anterior.

FREITAS, Roberto. A Dança na Educação Básica da rede pública municipal de ensino de Teresina/Piauí- uma realidade em crescimento. Revista da FUNDARTE, Montenegro, p.298-315, ano 19, no 37, Janeiro/Março.

Disponível em: http://.seer.fundarte.rs.gov.br/index.php/RevistadaFundarte/index> 30 de março de 2019. 


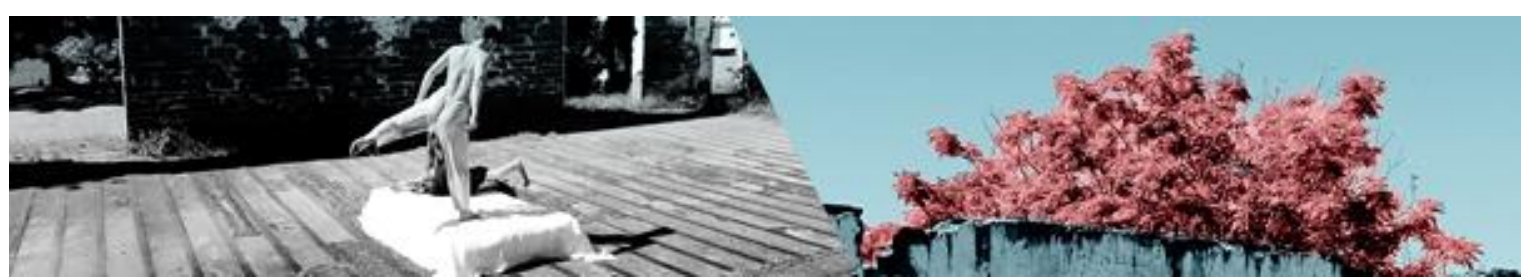

Outra atividade realizada que se comunica com aquelas ideias do parágrafo anterior - e que culminou em importantes resultados relativos à abertura dos estudantes para se expressarem, para externarem suas próprias ideias - foi a prática de Rodas de Conversa. Nestas se trabalhou a ideia de analisar as atividades propostas sem a premissa do certo e do errado, ou seja, sem se preocupar em experimentá-las de uma só forma determinada (todas as formas seriam válidas), restando analisar não só os resultados obtidos como também o processo percorrido que levou a tais resultados. Essa prática acabou por contribuir também para a elevação da autoestima dos estudantes que, cada vez mais, tornavam-se confiantes em si mesmos, não só para falar como também para se mover de diferentes formas, por diferentes caminhos.

Dentre os relatos feitos pela equipe de professores, também aparecem como resultantes do trabalho realizado, a melhora na "atenção, o intelecto, o respeito, a cidadania [...] ferramentas que servem de combate ao bullying e a violência moral e física, dentre muitas outras" (depoimento da professora Caroline Henrique Nunes da Silva, entregue sob a forma de relatório em dezembro de 2018).

Após refletir e discutir sobre como seria encerrado o ano letivo da dança, pensamento em comum com as outras disciplinas do núcleo diversificado, decidimos realizar uma mostra na qual cada escola apresentaria algum trabalho resultante das atividades já experimentadas, que deveriam ser revistas e tratadas como processo de pesquisa para criação em Dança. Para tal mostra, decidimos também um tema central: Valores Humanos. Cada trabalho teve como principal fio condutor um valor diferente (Ética, Honestidade, Cooperação, dentre outros), compondo, em conjunto, um grande mosaico de valores que foram experimentados, pesquisados e performados por novos caminhos, diferentes das formas já conhecidas pelos estudantes.

A mostra de dança tomou corpo no Teatro do Boi, em meio às mostras das outras linguagens artísticas que iam compondo um grande festival, e que, sem maiores pretensões, atravessaram-se ao ponto de ter trabalhos produzidos em um mix de várias linguagens: estudantes cantando, dançando, interpretando, produzindo seus próprios figurinos, cenários e até vídeos (de dança, de teatro, de protagonismo, de vida). A realização da mostra encarnou todos os pensamentos estudados e FREITAS, Roberto. A Dança na Educação Básica da rede pública municipal de ensino de Teresina/Piauí- uma realidade em crescimento. Revista da FUNDARTE, Montenegro, p.298-315, ano 19, no 37, Janeiro/Março.

Disponível em: http://.seer.fundarte.rs.gov.br/index.php/RevistadaFundarte/index> 30 de março de 2019. 


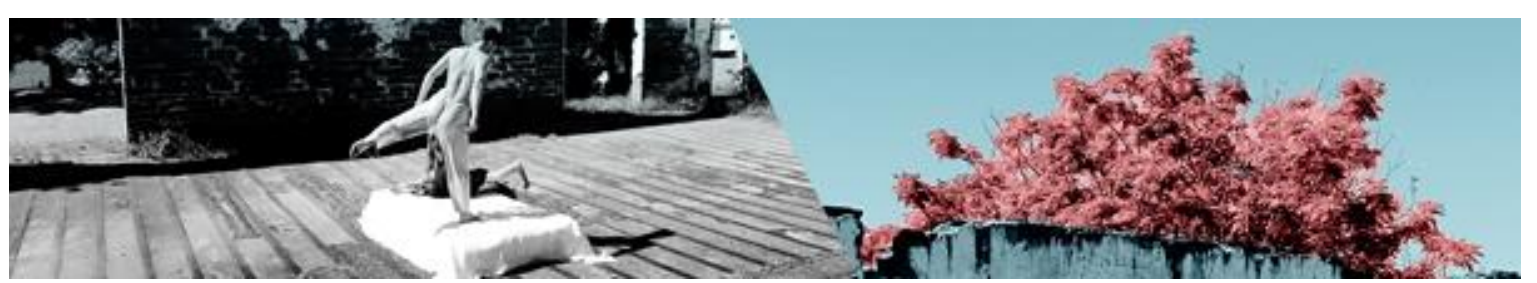

experimentados durante o ano, acabando por se transformar em uma grande confraternização de estudantes, entre os quais, somando-se aos professores, pessoas que, cada vez mais, melhor reconhecem a si mesmas e às outras ao seu redor.

\section{CONCLUSÕES SÃO SEMPRE CONTEXTUAIS}

Ao longo do ano de 2018, a vivência aproximada ao mundo da dança ${ }^{5}$ pôde proporcionar para estudantes e educadores da Rede Pública Municipal de Ensino de Teresina, a percepção da multiplicidade de relações que se processa entre o corpo humano e o mundo, bem como as diversas conexões que operam em nossas vidas e as inúmeras trajetórias que podem ser criadas a partir dessas relações/conexões.

Durante aquele ano, estudantes de Escolas Municipais em Teresina puderam experimentar a liberdade de colocar seu corpo inteiro para pensar, puderam ramificar suas ideias para além da caixa em que muitos se encontram, uma caixa moldada pela cultura que, em sua maior parte, é imposta pelo sistema, a começar pelos pais e mães que, vindos de outras criações, na maior parte do tempo, limitamse a reproduzir conceitos, ou pré-conceitos, sem dar liberdade para estes novos/outros corpos, que vivem em novos/outros tempos.

Os documentos mais recentes, que regem as diretrizes para a educação brasileira na contemporaneidade, tentam despertar os profissionais da educação para uma maior abertura do sensível, ou seja, para a percepção de que o desenvolvimento socioemocional e afetivo dos estudantes é tão importante quanto o desenvolvimento de seus domínios antes privilegiados (aqui considerando o cognitivo e o corporal). Porém, devido a outras formas de criação/formação/educação a que fomos submetidos, nós, as pessoas adultas, pais/mães, professores, educadores em geral, temos o impulso de nos relacionarmos com o mundo por meio de fazeres colonizadores $e$, nesse entendimento, queremos que o outro seja do jeito que nós desejamos, não dando margem para se mostrarem como verdadeiramente são.

\footnotetext{
${ }^{5}$ Expressão comum entre as pessoas que vivenciam a dança cotidiana e/ou profissionalmente.
}

FREITAS, Roberto. A Dança na Educação Básica da rede pública municipal de ensino de Teresina/Piauí- uma realidade em crescimento. Revista da FUNDARTE, Montenegro, p.298-315, ano 19, no 37, Janeiro/Março.

Disponível em: http://.seer.fundarte.rs.gov.br/index.php/RevistadaFundarte/index> 30 de março de 2019. 


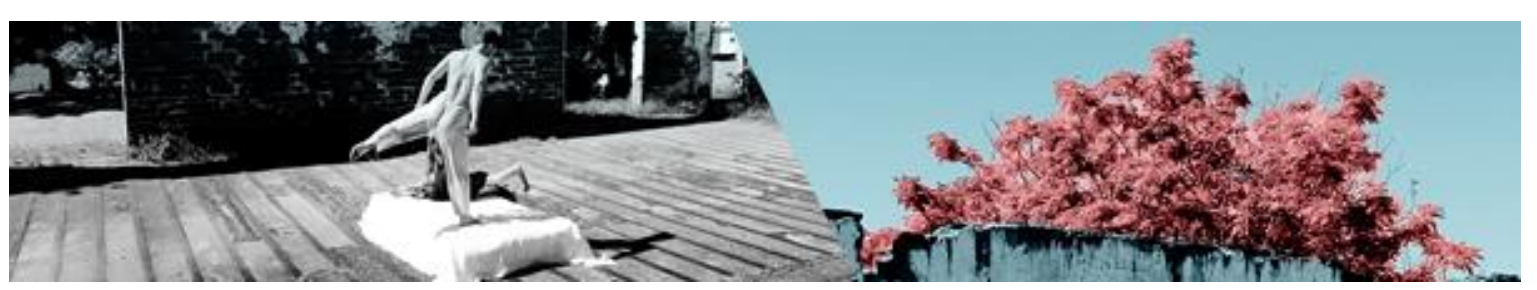

As praticas educativas a serem realizadas nos dias de hoje devem ser imbricadas de possibilidades de interação entre os corpos e o mundo, por meio de processos de ensino e de aprendizagem que utilizem pensamentos e ações que realmente promovam uma educação integral.

$\mathrm{Na}$ Dança, brinquedos cantados, rodas de movimentos, improvisações, estudos dos corpos, de tempos, de espaços, dentre tantas outras atividades realizadas, acabaram por resultar em comportamentos, falas e atitudes que validam essa iniciativa como um caminho acertado. Não tenho dúvidas para concordar:

Que seja perdido um único dia em que não se dançou.

Friedrich Nietzsche

\section{Referências:}

ADAD, Shara Jane Holanda Costa. A sociopoética e os cinco princípios: a filosofia dos corpos misturados na pesquisa em educação. In ADAD, Shara Jane Holanda Costa, PETIT, Sandra Haydèe, SANTOS, Iraci dos, GALTHIER, Jacques. Org. Tudo que não inventamos é falso: dispositivos artísticos para pesquisar, ensinar e aprender com a sociopoética. Fortaleza: EdUECE, 2014. (Práticas Educativas n. 6).

ARAÚJO, Maria Eliane dos Santos. Entrevista concedida ao autor em 09 de fevereiro de 2019.

BONDÍA, Jorge Larrosa. Notas sobre a experiência e o saber de experiência. Trad. João Wanderley Geraldi. Revista Brasileira de Educação. n. 19. Jan/fev/mar/abr 2002. p. 20-28.

BRASIL. Ministério da Educação. Base Nacional Comum Curricular. Brasília: MEC, 2018. Disponível em: <http://basenacionalcomum.mec.gov.br/>. Acesso em: 30 jul. 2018.

BRASIL. Constituição da República Federativa do Brasil. Edição 2013/2014. Brasília, DF: Senado Federal, 2013.

DELEUZE, Gilles, GUATARRI, Félix. Mil platôs: capitalismo e esquizofrenia 2. Vol 1. Trad. Ana Lucia de Oliveira, Aurélio Guerra Neto e Célia Pinto Costa. $2^{\underline{a}}$ ed. $1^{\underline{a}}$ reimp. São Paulo: Editora 34, 2014. (TRANS)

FREITAS, Roberto. A Dança na Educação Básica da rede pública municipal de ensino de Teresina/Piauí- uma realidade em crescimento. Revista da FUNDARTE, Montenegro, p.298-315, ano 19, no 37, Janeiro/Março.

Disponível em: http://.seer.fundarte.rs.gov.br/index.php/RevistadaFundarte/index> 30 de março de 2019. 


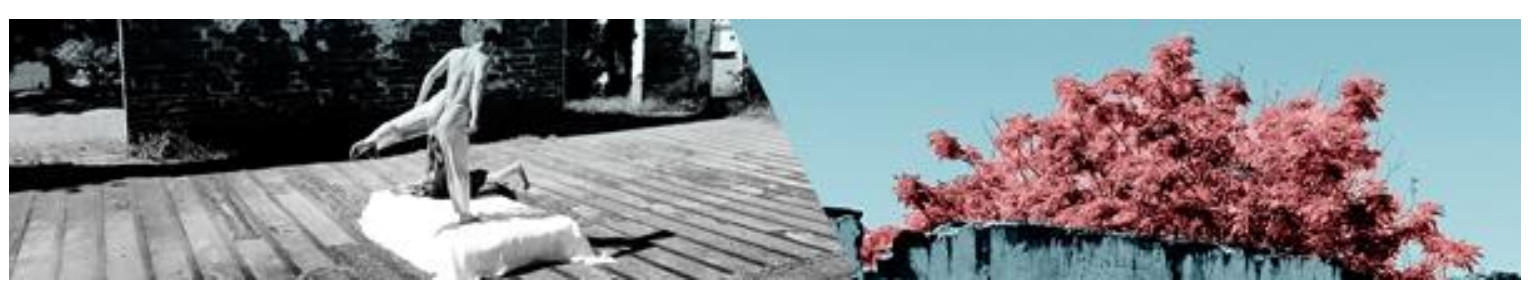

FREIRE, Paulo. A importância do ato de ler: em três artigos que se completam. 23a ed. São Paulo: Autores Associados: Cortez, 1989. (Polêmicas do nosso tempo - 4).

FREIRE, Paulo. Pedagogia do oprimido. $17^{\mathrm{a}}$ ed. Rio de Janeiro: Paz e Terra, 1987. (Coleção O mundo, hoje, v. 21).

FREITAS, Francisco Roberto de. Corpo Cordão: cartografias de jovens dançantes em Teresina - Piauí. Dissertação de mestrado apresentada ao Programa de PósGraduação em Artes Cênicas da Universidade de Brasília - PPGCEN/UnB, 2017. Disponível em <http://repositorio.unb.br/handle/10482/23678>. Acesso em 01/02/2019.

FREITAS, Roberto; BREBIS, Flavio. Arte, educação e inclusão: 10 anos de cordão grupo de dança. Teresina: Gráfica SP Ltda, 2018.

LE BRETON, David. Antropologia do corpo e modernidade. Trad. Fábio dos Santos Creder Lopes, 3ํㅡㄹ ed. Petrópolis: Vozes, 2013.

MARQUES, Isabel A. O ensino de dança hoje: textos e contextos. $6^{\underline{a}}$ ed. São Paulo: Cortez, 2011.

SETENTA, Jussara Sobreira. O fazer-dizer do corpo: dança e performatividade. Salvador: EDUFBA, 2008.

STRAZZACAPPA, Márcia; MORANDI, Carla. Entre a arte e a docência: a formação do artista da dança. $4^{\underline{a}}$ ed. Campinas: Papirus, 2012. Coleção Ágere.

SANTOS, Juliana de Paula Guedes de Melo. A escola de tempo integral no brasil: histórico, reflexões e perspectivas. Trabalho apresentado no XI Encontro de Pesquisadores do Programa de Pós-Graduação em Educação: currículos - tempos, espaços e contextos. PUC-SP, 2013. Disponível em < https://www.pucsp.br/webcurriculo/edicoes anteriores/encontropesquisadores/2013/downloads/anais encontro 2013/poster/juliana paula guedes melo santos.pdf> Acesso em 04 fev 2019.

ZEICHNER, Kenneth M. A formação reflexiva de professores: ideias e práticas. Lisboa: Educa, 1993.

FREITAS, Roberto. A Dança na Educação Básica da rede pública municipal de ensino de Teresina/Piauí- uma realidade em crescimento. Revista da FUNDARTE, Montenegro, p.298-315, ano 19, no 37, Janeiro/Março.

Disponível em: http://.seer.fundarte.rs.gov.br/index.php/RevistadaFundarte/index> 30 de março de 2019. 